\title{
Characterisation of Gas Transport Properties of the Opalinus Clay, a Potential Host Rock Formation for Radioactive Waste Disposal
}

\author{
P. Marschall' ${ }^{1}$ S. Horseman ${ }^{2 *}$ and T. Gimmi ${ }^{3}$ \\ 1 NAGRA, National Cooperative for the Disposal of Radioactive Waste, Hardstr. 73, 5200 Wettingen - Switzerland \\ 2 British Geological Survey, Kingsley Dunham Centre, Keyworth, Nottingham NG12 5 GG - United Kingdom \\ 3 Universitity of Bern, Baltzerstrasse 1-3, 3012 Bern and Paul Scherrer Institut, 5232 Villigen - Switzerland \\ e-mail: marschall@nagra.ch - stho@bgs.ac.uk-gimmi@geo.unibe.ch
}

* The contribution to this work by Steve Horseman, who died suddenly last year, is greatly appreciated by the remaining authors. His loss is regretted by his colleagues.

\begin{abstract}
Résumé - Caractérisation des propriétés des argiles d'Opalinus (roche d'accueil potentielle pour un stockage de déchets radioactifs) relatives au transport des gaz — Les argiles d'Opalinus, au nord de la Suisse, sont envisagées pour l'implantation d'un site de stockage pour déchets radioactifs en formation géologique profonde. La compréhension approfondie des processus de transport des gaz au travers de cette roche peu perméable est un élément clé dans l'évaluation de l'aptitude du site au stockage. Selon les données fournies par les campagnes de reconnaissance géologique et les expériences en laboratoire, la perméabilité intrinsèque d'argiles d'Opalinus serait de l'ordre de $10^{-20}$ à $10^{-21} \mathrm{~m}^{2}$, pour un rapport d'anisotropie modéré $(<10)$. La porosité dépend de la composition de l'argile et de la profondeur d'enfouissement; pour la zone envisagée, on a mesuré des valeurs de l'ordre de $\sim 0,12$. Selon les données porosimétriques, on peut classer 10-30\% des vides dans la catégorie des macropores, avec un diamètre équivalent $>25 \mathrm{~nm}$. Les pressions d'entrée déterminées sont de l'ordre de 0.4-10 MPa et dépendent largement de la perméabilité intrinsèque. Les tests, tant in situ qu'en laboratoire (essais par perméamètre au gaz sur les carottes de forage), montrent un fort couplage entre la migration de gaz à travers la roche et les déplacements de l'eau interstitielle. Il semblerait donc possible d'appliquer les modèles de déplacement immiscible de fluides dans les milieux poreux, et ceci lorsque la pression d'entrée du gaz (c'est-à-dire le seuil de pression capillaire) est inférieure au niveau minimal de contrainte au sein de la roche. Il faut noter que la circulation de gaz est limitée au réseau des macropores connectés entre eux, d'où un très faible degré de désaturation de la roche au cours du processus d'imbibition du gaz. Lorsque que la pression du gaz est élevée (c'est-à-dire lorsqu'elle approche le niveau de la contrainte maximale exercée sur la roche), on a pu observer des mécanismes de transport induits par effet de dilatation. Par le biais d'autres expériences de terrain, on a tenté de produire des fractures de rupture de grande extension et à haute transmissivité (hydrofracs, gasfracs). Les résultats de ces tests permettent de conclure que la fracturation due aux gaz peut, dans une large mesure, être exclue des risques inhérents au comportement d'un dépôt après fermeture.
\end{abstract}

\footnotetext{
Abstract - Characterisation of Gas Transport Properties of the Opalinus Clay, a Potential Host Rock Formation for Radioactive Waste Disposal - The Opalinus Clay in Northern Switzerland has been identified as a potential host rock formation for the disposal of radioactive waste. Comprehensive understanding of gas transport processes through this low-permeability formation forms a key issue in
} 
the assessment of repository performance. Field investigations and laboratory experiments suggest an intrinsic permeability of the Opalinus Clay in the order of $10^{-20}$ to $10^{-21} \mathrm{~m}^{2}$ and a moderate anisotropy ratio < 10. Porosity depends on clay content and burial depth; values of $\sim 0.12$ are reported for the region of interest. Porosimetry indicates that about 10-30\% of voids can be classed as macropores, corresponding to an equivalent pore radius $>25 \mathrm{~nm}$. The determined entry pressures are in the range of 0.4-10 MPa and exhibit a marked dependence on intrinsic permeability. Both in situ gas tests and gas permeameter tests on drillcores demonstrate that gas transport through the rock is accompanied by porewater displacement, suggesting that classical flow concepts of immiscible displacement in porous media can be applied when the gas entry pressure (i.e. capillary threshold pressure) is less than the minimum principal stress acting within the rock. Essentially, the pore space accessible to gas flow is restricted to the network of connected macropores, which implies a very low degree of desaturation of the rock during the gas imbibition process. At elevated gas pressures (i.e. when gas pressure approaches the level of total stress that acts on the rock body), evidence was seen for dilatancy controlled gas transport mechanisms. Further field experiments were aimed at creating extended tensile fractures with high fracture transmissivity (hydro- or gasfracs). The test results lead to the conclusion that gas fracturing can be largely ruled out as a risk for post-closure repository performance.

\section{INTRODUCTION}

Radioactive wastes conditioned for geological disposal in deep, low-permeability formations will produce a significant amount of gas due to corrosion and degradation processes. Gas generation will continue for a long period after repository closure and the accumulation of the gas may lead to unacceptable build-up of gas pressure in the disposal tunnels, if the gas cannot escape through the low-permeability host rock. Consequently, the investigation of gas transport processes is of high relevance in the assessment of repository performance.

As part of the Swiss waste disposal programme, gas transport processes were studied in a potential host rock called the Opalinus Clay (Nagra, 2002a; Nagra, 2002b; Nagra, 2004). The investigations concentrated on the Zürcher Weinland in Northern Switzerland, with a deep investigation borehole close to the village of Benken, and on the Mont Terri Rock Laboratory located in the Folded Jura of north-west Switzerland near the town of St-Ursanne (Thury and Bossart 1999). Field investigations included hydraulic packer tests and gas injection tests in boreholes, complemented by studies of the unsaturated zone around ventilated tunnels in the Mont Terri Rock Laboratory. The laboratory investigations on Opalinus Clay drillcores from Benken and Mont Terri comprised microstructural analyses, determination of the capillary pressure relationship and gas permeability measurements in isostatic cells.

\section{THE OPALINUS CLAY FORMATION}

The Opalinus Clay was deposited $180 \mathrm{Ma}$ ago in a shallow marine environment. It is part of a thick Mesozoic-Tertiary sedimentary sequence in the Molasse Basin of Northern Switzerland. In the siting area, the Mesozoic sediments reveal uniform thickness over a distance of several kilometres, dipping gently to the south-east, and are hardly affected by faulting. Regional geological investigations in Northern Switzerland and more focused studies in the Zürcher Weinland with a 3D seismic survey and a borehole at Benken confirmed the remarkable homogeneity of the Opalinus Clay on the site scale (Birkhäuser et al., 2001; Nagra, 2001; Müller et al. 2002).

The Opalinus Clay formation is a moderately overconsolidated claystone that has been formed by a complex burial and compaction history with two distinct periods of subsidence. In the region of the Zürcher Weinland, the formation reached a burial depth of about $1000 \mathrm{~m}$ during the Cretaceous. A period of uplift of the area in the mid-Tertiary was followed by subsidence in the late Tertiary, when the Opalinus Clay reached its greatest burial depth of about $1700 \mathrm{~m}$ below the surface. From about $10 \mathrm{Ma}$ ago, alpine uplift and erosion brought the Opalinus Clay progressively up to its present burial depth of about $600-700 \mathrm{~m}$ in the region of interest. At Mont Terri, the Opalinus Clay formation reached a maximum depth of about $1000 \mathrm{~m}$ and the present burial depth is about $200-300 \mathrm{~m}$.

On a regional scale, the mineralogical composition of the Opalinus Clay (Nagra 2002a) exhibits moderate lateral variability and a slight increase in clay content with depth. Quantitative laboratory analyses of core samples from Benken and Mont Terri provided a total mass fraction of clay minerals of $54-66 \%$, a quartz content of $14-20 \%$ and $13-16 \%$ calcite. The fraction of swelling clay minerals, with $11-14 \%$ illite/smectite mixed layers, is of particular interest for the gas-related studies. Further minerals are siderite, pyrite and feldspar. The mass fraction of organic carbon is $<1 \%$.

Transport of non-wetting fluids in a low-permeability formation is largely controlled by the microstructure of the rock. A balanced assessment of gas transport processes in the Opalinus Clay therefore requires careful consideration of both structure and texture. Figure 1 illustrates the mineralogical and structural features of the Opalinus Clay in the 
Zürcher Weinland on various scales. Petrophysical logs in the Benken borehole indicate moderate variability and a slight increase of clay content with depth, suggesting a division of the Opalinus Clay into 5 lithostratigraphic sub-units (facies). Core inspection reveals a distinct anisotropy, made up of siderite concretions and silt and sandstone lenses, which are embedded in the clay-rich strata. The anisotropy due to bedding is largely a result of microscopic heterogeneity as seen in the thin sections, where diagenetic cementation of the pore space has been observed in the silty and sandy layers. Scanning electron microscope (SEM) images reveal that the size of the mineralogical components $\left(10^{-7}-10^{-3} \mathrm{~m}\right)$ determines the microstructure of the rock. Quartz minerals may exhibit grain sizes in the range $0.01 \mathrm{~mm}$, whereas the clay minerals form flake-like packages with typical sizes in the order of $100 \mathrm{~nm}-10 \mu \mathrm{m}$. The pore space of the rock is formed by a network of micro/meso- and macropores, which is too small (in the order $1-100 \mathrm{~nm}$ ) to be shown by conventional SEM methods. This network of pores actually dominates the flow and transport properties of the rock. As shown in the subsequent section, complementary methods are required to characterise the pore space of the Opalinus Clay, such as mercury porosimetry and measurement of the adsorption / desorption isotherms.

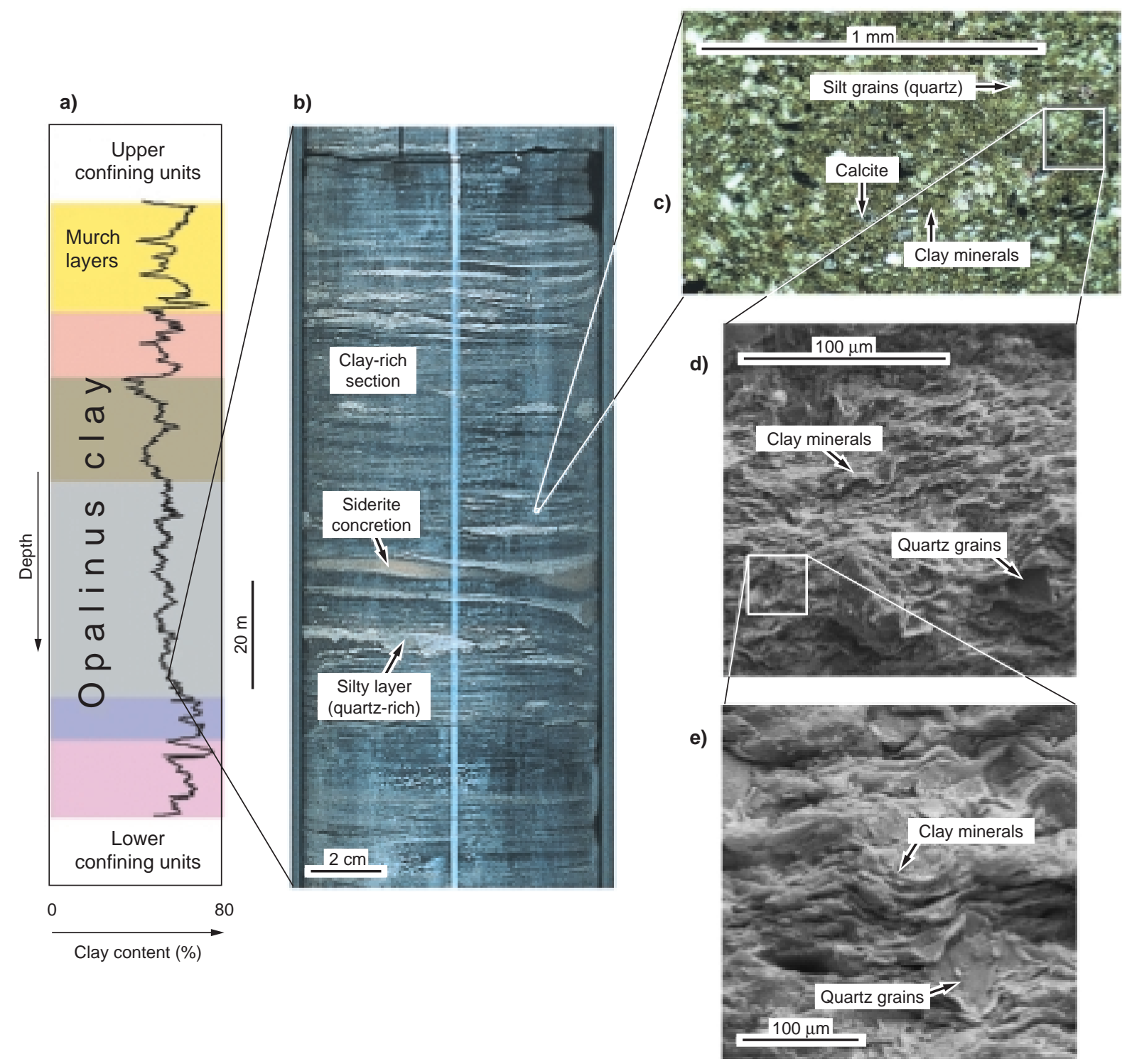

Figure 1

Illustration of the mineralogy and structure of the Opalinus Clay at different scales, based on data from the Benken borehole in the Zürcher Weinland: a) vertical profile of clay content determined by petrophysical logging; b) core sample; (c) thin sections and (d+e) SEM images (after Nagra, 2002a). 
a) Phenomenological description

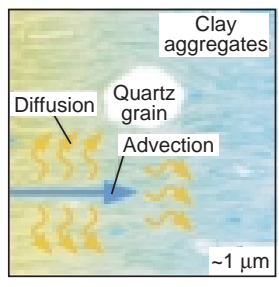

Advection and diffusion of dissolved gas

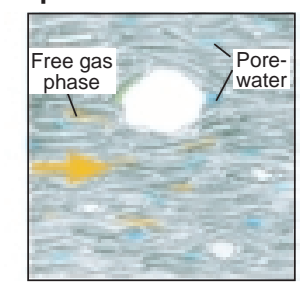

Viso-capillary flow of gas and water phase ("two-phase flow")

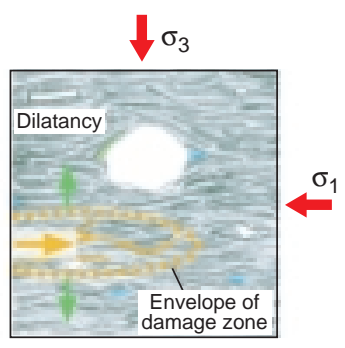

Dilatancy controlled gas flow ("pathway dilation")

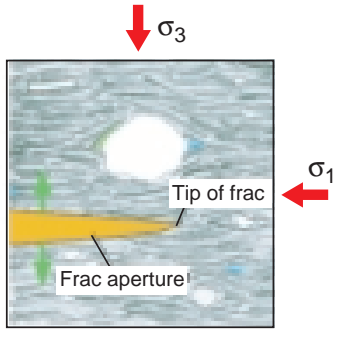

Gas transport in tensile fractures ("hydro-/gasfrac")

b) Transport mechanisms

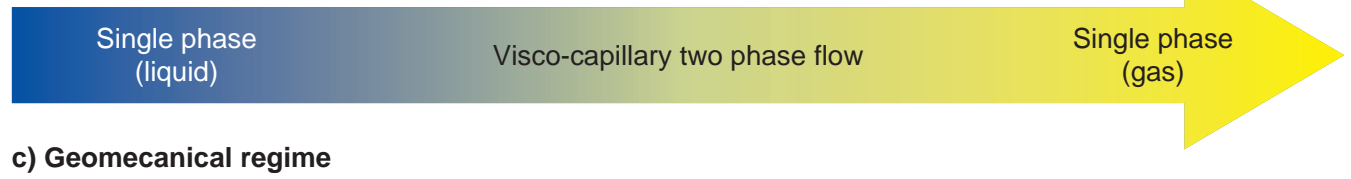

\section{c) Geomecanical regime}

Poro-elastic deformation
Irreversible deformation

Dilatancy

Distributed shear

failure

d) Barrier function of host rock

Not affected
Dilatancy-controlled permeability
Distinct fracture transmissivity

Figure 2

Classification and analysis of gas transport processes in Opalinus Clay: a) phenomenological description based on the microstructural model concept; b) basic transport mechanisms; c) geomechanical regime; and d) effect of gas transport on the barrier function of the host rock.

\section{BASIC CONCEPTS OF GAS TRANSPORT}

Gas transport through low-permeability rock formations is controlled not only by the hydraulic and mechanical properties of the rock mass (intrinsic permeability, porosity, rock strength), but also by the gas pressure at the generation locus and the hydromechanical state of the rock (i.e. water saturation, porewater pressure, stress state). Phenomenological considerations suggest the following subdivision of the basic transport mechanisms (Fig. 2):

- advective-diffusive transport of gas dissolved in the porewater;

- visco-capillary two-phase flow;

- dilatancy-controlled gas flow;

- gas transport along macroscopic tensile fractures (hydroand gas-fracturing).

As seen in Figure 2a, the phenomenological description is inspired by the microstructural conceptualisation of the Opalinus Clay (Nagra, 2002a). The complex hydromechanical processes are decomposed into a problem of transport of immiscible fluids (Figure $2 b$ ) and a geomechanical problem (Figure 2c). The effect of gas transport on the hydraulic barrier function of the rock is highlighted for each of the transport mechanisms (Figure 2d). The different mechanisms are discussed in the following sections.

\subsection{Transport of Gas Dissolved in the Porewater}

Advective and diffusive transport of gas dissolved in porewater is characterised by three fundamental laws. The advective groundwater flow is governed by Darcy's law. Fick's law represents the diffusion of dissolved gas due to concentration gradients in the porewater and Henry's law describes the solubility of gas in porewater (Helmig, 1997). The transport of dissolved gas occurs even at low (total) gas pressures; the pressure-dependent dissolution of gas in porewater and the increased groundwater flux cause the specific flux of the dissolved gas to increase with an increase in the gas pressure. The main parameters affecting the transport behaviour of dissolved gas are Henry's coefficient, the diffusion coefficient in water, the tortuosity, the accessible porosity and the hydraulic conductivity. The low hydraulic conductivity of argillaceous rock significantly restricts the efficiency of this transport mechanism. Nevertheless, the general importance of diffusion and advection as slow background processes in all types of cap rock formations is beyond question and has been addressed in the context of many hydrocarbon exploration and reservoir engineering studies (Clayton and Hay, 1994; Krooss et al., 1992; Schlömer and Krooss, 1997). 


\subsection{Visco-Capillary Two-Phase Flow}

In its conventional form, visco-capillary two-phase flow is described as a transport process whereby porewater in the pore volume of a rock formation is displaced by gas under the influence of viscous and capillary forces (e.g. Bear, 1972). In a geomechanical sense, the rock mass behaves like an elastic medium, characterised by the porosity and the rock compressibility. The controlling factor for the two-phase flow characteristics of a porous medium is the gas entry pressure $p_{a e}$, also known as the capillary threshold pressure, which represents the difference between gas pressure and water pressure needed to displace the porewater from the initially fully saturated medium. For a capillary tube, Young's equation gives the relationship between the gas entry pressure (capillary threshold pressure) and the pore radius:

$$
p_{a e}=\frac{2 \cdot \sigma_{g w}}{r} \cos \alpha
$$

where $p_{a e}$ is the gas entry pressure, $\sigma_{g w}$ is the surface tension gas/water (ca. $0.073 \mathrm{~N} \mathrm{~m}^{-1}$ at $20^{\circ} \mathrm{C}$ ), $r$ represents the radius of the capillary tube and $\alpha$ is the wetting angle. In porous media, Young's equation can be adopted to define an equivalent pore radius of the medium by measuring the entry pressure with a non-wetting fluid (e.g. mercury porosimetry).

Once the gas entry pressure has been exceeded, the gas mobility is controlled mostly by the intrinsic permeability $k$ of the formation, the permeability-saturation relationship (relative permeability), and the relationship between the capillary pressure and the water saturation (suction or water retention curve). The functional dependency between the pore space saturation and the relative permeability or the capillary pressure are commonly described with parametric models. According to van Genuchten (1980), the functional relationship between water saturation and capillary pressure is given as:

$$
p_{c}=\frac{1}{\alpha} \cdot\left(S_{e c} \frac{n}{1-n}-1\right)^{\frac{1}{n}} \quad \text { with } \quad S_{e c}=\frac{S_{w}-S_{w r}}{1-S_{w r}}
$$

where $p_{c}$ represents the capillary pressure. $1 / \alpha$, the inverse of van Genuchten's $\alpha$ parameter, is known as the apparent gas entry pressure and $n$ is the shape factor (pore size distribution index). The effective saturation $S_{e c}$ can be determined when the actual porewater saturation $S_{w}$ (volume of porewater per volume of pores) and the residual porewater saturation $S_{w r}$ are given.

The relative gas/water permeabilities $k_{r, g}$ and $k_{r, w}$ of the Opalinus Clay are described by the approach of Mualem (e.g. Helmig, 1997).

$$
\begin{aligned}
& k_{r, g}=\left(1-S_{e}\right)^{\varepsilon} \cdot\left(1-S_{e} \frac{n}{n-1}\right)^{2(1-1 / n)} \\
& k_{r, w}=S_{e}^{\gamma} \cdot\left[1-\left(1-S_{e} \frac{n}{n-1}\right)^{\frac{n-1}{n}}\right]^{2}
\end{aligned}
$$

with:

$$
S_{e}=\frac{S_{w}-S_{w r}}{1-S_{g r}-S_{w r}}
$$

where $\varepsilon$ and $\gamma$ are empirical shape factors, describing the pore connectivity of the medium (present study: $\varepsilon=\gamma=0.5$ ). According to the Mualem approach, the definition of the effective saturation $S_{e}$ is slightly modified and includes the residual gas saturation $S_{g r}$.

A distinct hysteresis is often seen in the capillary pressure relationship, when a porous medium is saturated or desaturated, respectively. The porosity of the medium cannot be saturated completely during the saturation process (residual gas saturation $S_{g r}$ ), because part of the pore space is poorly connected. On the other hand, assuming an initially fully saturated medium, a critical gas saturation has to be exceeded before gas starts to form a continuous phase with a gas permeability > 0 (e.g. Dury et al., 1999). In the context of this study, due to the limited experimental data base, no distinction is made between residual and critical gas saturation.

\subsection{Dilatancy-Controlled Gas Flow}

Dilatancy controlled gas flow (or "pathway dilation"; terminology after Horseman et al., 1996) is a transport mechanism of special importance for argillaceous media with low tensile strength. Clay-rich rock cannot withstand long-term gas pressures with a magnitude greater than the minimum principal stress acting on the rock mass. Due to the expected microscale variability of the geomechanical rock properties, it even seems plausible that microfractures will form before the level of minimum principal stress is reached. Gas flow along microfractures is anticipated in situations where the shear stress is large in comparison with peak strength or where the stress state favours extensile rock deformation. The process of gas-driven microfracturing leads to an increase of the pore space, which is accompanied by a detectable increase in intrinsic permeability and a change in the capillary pressuresaturation relationship. In the terminology of multiphase flow concepts, gas flow is still controlled by visco-capillary forces (phase interference between wetting and nonwetting fluid)the main difference with respect to conventional two-phase flow is that the transport properties of the solid phase (rock permeability, relative permeability, capillary pressure relationship) can no longer be viewed as invariants since they depend on the state of deformation of the rock. 


\subsection{Gas Flow Along Macroscopic Tensile Fractures}

As a rule of thumb, a macroscopic tensile fracture (hydrofrac/ gasfrac) develops when the gas pressure is larger than the sum of the minimum principal stress and the tensile strength of the rock (e.g. Valko and Economides, 1997). The macroscopic fracture is initiated quasi-instantaneously and propagates at about the velocity of a shear wave. Gas flow in such a macroscopic tensile fracture can be seen as a single-phase flow process. The propagation comes to a halt when the gas pressure in the fracture becomes less than the value of the minimum principal stress (shut-in pressure). Successful hydrofracs are characterised by a fracture transmissivity which increases the bulk permeability of the treated rock by many orders of magnitude. In a rock with low tensile strength, a macroscopic frac develops only when the gas pressure build-up is rapid, i.e. when the combined effect of porewater displacement and formation of small-scale fractures (i.e. dilatancy) no longer counterbalances the gas production rate. The conceptual, theoretical and experimental framework for fracture propagation is well documented in standard hydrocarbon exploration literature (e.g. Valko and Economides, 1997).

\section{LABORATORY EXPERIMENTS}

As part of the rock characterisation programme, laboratory analyses were performed with core samples of Opalinus Clay from Benken and Mont Terri. Table 1 presents typical values for the basic physical properties.

Of special interest for studies of gas transport are the pore size distribution and the water retention function (capillary pressure-saturation relationship) of Opalinus Clay. Because of the small sizes of the pores, no direct characterisation of the pore structure is possible and one has to rely on indirect methods like mercury porosimetry and measurements of nitrogen or water isotherms. In Section 3.1, we give a brief outline of the methods used and then discuss the results. Section 3.2 summarises the laboratory experiments on gas permeability measurements.

\subsection{Pore Size Distribution and Capillary Pressure}

Mercury porosimetry data and nitrogen and water isotherms were obtained at the geotechnical laboratories of $B R G M$ (Bureau de recherches géologiques et minières, Orléans, France) and LEM-CNRS (Laboratoire environnement et minéralurgie, Nancy, France), and summarised in Nagra (2002a). For mercury porosimetry, $\mathrm{Hg}$ was injected at increasing pressures into crushed, dried and degassed samples. From the incremental saturation and the Washburn Equation, which is equivalent to Young's Equation (1) for this system, the distribution of equivalent pore sizes was inferred. The maximum injection pressure was $200 \mathrm{MPa}$, and thus only pores with a radius larger than $3.7 \mathrm{~nm}$ could be detected. To obtain nitrogen and water isotherms, the powder samples were dried at temperatures of at least $120^{\circ} \mathrm{C}$ and degassed under vacuum. Nitrogen isotherms were measured at $77 \mathrm{~K}$, water isotherms at $303 \mathrm{~K}$ by gravimetry in quasi-equilibrium mode, where water vapour was introduced at a constant, low flow rate (Villiéras et al., 1997). The pore size distributions in the mesopore range (radius between 1 and $25 \mathrm{~nm}$; definition according to IUPAC 1997) were obtained from the incremental saturation and Young's Equation (1). In the case of narrow pores as in clay rocks, a correction for the amount of fluid adsorbed on surfaces, as opposed to condensed in capillaries, has to be made. This was done according to the Barret-Joyner-Hallenda (BJH)

TABLE 1

Basic physical properties of Opalinus Clay from Benken and the Mont Terri Rock Laboratory (Nagra, 2002a; Pearson et al., 2003)

\begin{tabular}{|c|c|c|c|c|c|}
\hline & \multicolumn{2}{|c|}{ Benken } & \multicolumn{2}{|c|}{ Mont Terri } & \multirow[t]{2}{*}{ Remarks } \\
\hline & Mean & Range & Mean & Range & \\
\hline Bulk dry density $\left(\mathrm{Mg} \mathrm{m}^{-3}\right)$ & 2.43 & $2.37-2.53$ & 2.31 & $2.28-2.32$ & \\
\hline Grain density $\left(\mathrm{Mg} \mathrm{m}^{-3}\right)$ & 2.72 & $2.69-2.74$ & 2.74 & $2.70-2.77$ & \\
\hline Water loss porosity (-) & $0.11^{(\mathrm{a})}$ & & $0.16^{(\mathrm{a})}$ & & Drying at $105^{\circ} \mathrm{C}$ \\
\hline Specific surface area ${ }^{(b)}$ BET $N_{2}\left(m^{2} g^{-1}\right)$ & & $19-49$ & & $24-37$ & External surfaces \\
\hline $\begin{array}{l}\text { Specific surface area } \\
\text { EGME or } \mathrm{H}_{2} \mathrm{O}\left(\mathrm{m}^{2} \mathrm{~g}^{-1}\right)\end{array}$ & & $56-129$ & & $112-147$ & $\begin{array}{c}\text { Total surfaces, various } \\
\text { methods }\end{array}$ \\
\hline
\end{tabular}

a: not all water will be driven off at $105^{\circ} \mathrm{C}$; for Benken, the physical porosity is estimated to be about $1.1-1.2$ times the water loss porosity, or somewhere in the range 0.12 0.13 .

b: nitrogen cannot penetrate into the interlayer space, i.e. the pores between basic clay layers of expandable clays (smectites). Thus, only external surfaces are reached by nitrogen.

c: EGME (ethylene glycol monoethyl ether) is a polar liquid, which can, like water, also penetrate the interlayer space of expandable clays. Thus, EGME and $\mathrm{H}_{2} \mathrm{O}$ are considered to reach all surface areas. 


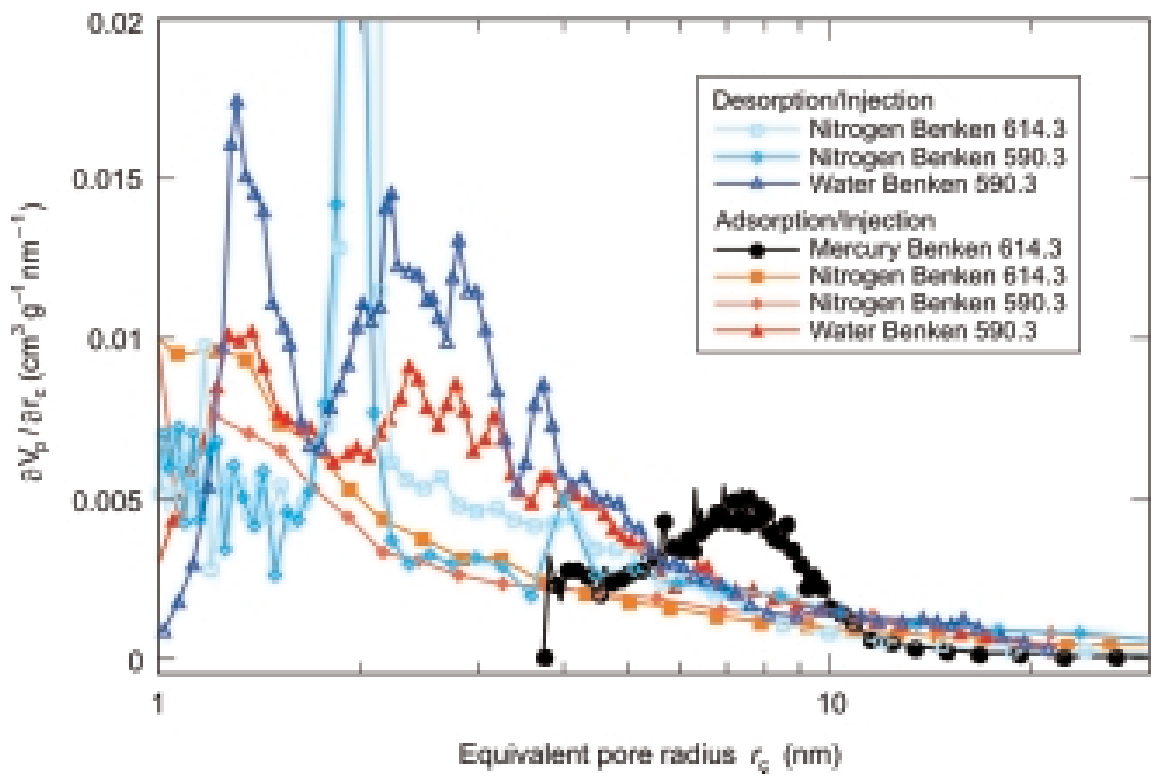

Figure 3

Equivalent pore size distributions in the mesopore range (equivalent pore radii $1 \mathrm{~nm} \leq r_{c} \leq 25 \mathrm{~nm}$ ). Pore size distribution in terms of incremental pore volume per size class, $\partial V_{p} / \partial r_{c}$, as obtained from mercury injection, nitrogen adsorption and desorption, and water adsorption and desorption. The numbers in the legend of the plot indicate the sampling depth in $\mathrm{m}$ below ground.

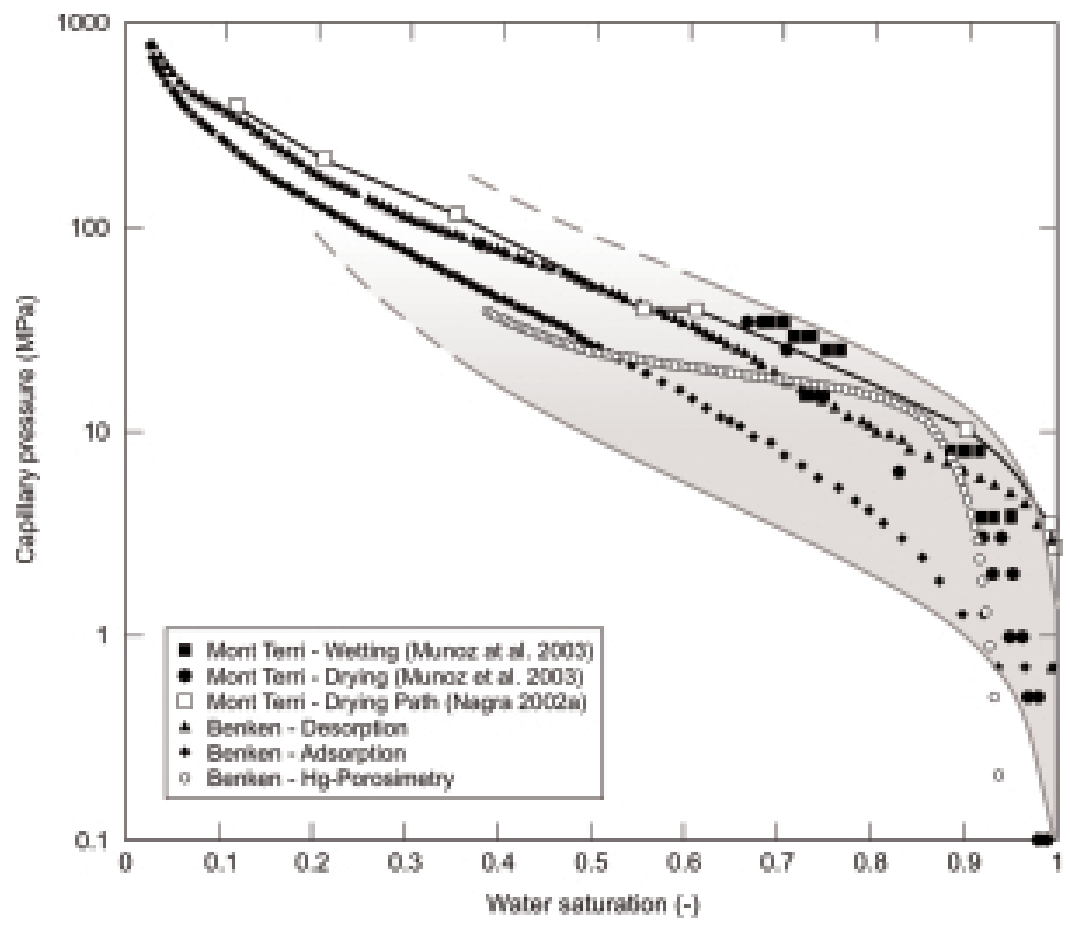

Figure 4

Capillary pressure - water saturation curves for Opalinus Clay samples from Mont Terri and Benken. Various methods were applied: water adsorption/desorption measurements, mercury porosimetry and controlled suction tests (Nagra, 2002a; Muñoz et al., 2003). 
method (Nagra, 2002a). Water retention functions describe the capacity of a porous medium to retain water at a given suction head. Thus, the water retention function is in principle identical to the water adsorption isotherm. The main differences are the experimental procedure and the preparation of the samples. Water retention curves of the Opalinus Clay were determined at the geotechnical laboratories of UPC (Universitat Politècnica de Catalunya, Barcelona, Spain), by stepwise desaturation and resaturation of core samples under controlled humidity (Nagra, 2002a; Muñoz et al., 2003).

Figure 3 shows a comparison of the pore size distributions in the mesopore range obtained from mercury injection, from the nitrogen isotherms and from the water isotherms for Benken samples. Distributions obtained from adsorption and desorption of nitrogen or water are shown. It is evident that the details of the distributions are rather different, depending on the method that was used. Thus, the results can only give a relatively general picture of typical size distributions, and interpretation of specific peaks obtained for one adsorbate should be done with care, having regard to possible interactions between the adsorbate and the solid surfaces.

From the mercury data, and assuming a physical porosity of the Opalinus Clay samples of 0.12 , the volume fraction of pores with radii larger than $25 \mathrm{~nm}$ was estimated to be about $10 \%$, the fraction with radii between 3.7 and $25 \mathrm{~nm}$ about $51 \%$, and the fraction with radii below $3.7 \mathrm{~nm}$ about $39 \%$. The isotherm data suggest a somewhat larger macropore fraction in the order of 20-30\%. From these numbers and from the curves in Figure 3, it becomes evident that a large proportion of the pores are very narrow, with equivalent radii smaller than about $10 \mathrm{~nm}$.

Figure 4 shows the water adsorption and desorption data and the mercury injection data interpreted as water retention functions (capillary pressure-saturation relationship). A physical porosity of 0.12 was used to calculate the saturation in the case of the mercury data. In the same plot, suction curve data obtained for Mont Terri samples are presented (Nagra, 2002a; Muñoz et al., 2003).

The water adsorption and desorption data show a clear hysteresis. This phenomenon is very common; it may be linked to pore connectivity, variability of cross-sections, or other effects. Notably, in the water retention curves of the Mont Terri samples such differences are not observed between the drying and wetting path (Nagra, 2002a; Muñoz et al., 2003), but the retention data are very similar to the water desorption isotherm of the Benken sample. The shape of the mercury curve differs slightly from that of the water isotherms, but it is located approximately within the range spanned by the hysteresis of the water isotherm. We attempted to adjust the parameters of a van Genuchten function (2) such that it fits the measured adsorption and desorption data approximately. The following values were obtained: $n=1.6, \alpha=0.065 \mathrm{MPa}^{-1}$ for desorption, $n=1.5$, $\alpha=0.14 \mathrm{MPa}^{-1}$, and a maximum saturation of 0.95 for adsorption. The corresponding apparent gas entry values, $1 / \alpha$, are about $7 \mathrm{MPa}$ and $15 \mathrm{MPa}$, respectively.

\subsection{Gas Permeability Measurements}

Six long-term gas permeability tests were conducted on Opalinus Clay core samples from the Mont Terri Underground Laboratory and from Benken. The experimental work was carried out by two different geotechnical laboratories, namely by SCK.CEN (Studiecentrum voor Kernenergie, Centre d'étude de l'énergie nucléaire, Mol, Belgium) and by BGS (British Geological Survey, Nottingham, United Kingdom). Both laboratories used isostatic cells, designed to match the expected in situ stress conditions by applying an isotropic confining pressure on the test sample. Testing of the ultra-low permeability rock samples turned out to be an extremely demanding task with respect to the experimental set-up and the test duration, typically in the order of several hundred days for a single core sample.

Figure 5a shows a schematic sketch of the BGS isostatic cell with the main components. The cylindrical rock specimen (diameter: $54 \mathrm{~mm}$, thickness: $34 \mathrm{~mm}$ ) is sandwiched between the end-caps and can be subject to an isotropic confining stress up to $40 \mathrm{MPa}$. The sample is jacketed in heat-shrink Teflon to exclude confining fluid. The inlet and outlet zones for water or gas flow through the specimen are provided by porous filter discs which are recessed into the bearing surface of the end-caps. Annular guard-ring filters are recessed into the end-caps so that they completely encircle the inlet and outlet filters. Volumetric total (i.e. gas and water) flow rates for the upstream and downstream side as well as the pressure of the inlet/outlet zones and of the guardring filters are monitored by a data acquisition system. A more detailed description of the basic permeameter system is given in Harrington et al. (2001).

Testing was performed in an air-conditioned laboratory at a temperature of $20 \pm 0.3^{\circ} \mathrm{C}$. A typical test history comprised a sequence of test stages, namely:

- a saturation and equilibration stage;

- a constant rate water flow stage;

- pressure recovery stage;

- a sequence of constant gas pressure (CP) test stages.

Saturation of the specimen and constant rate water testing were accomplished with a synthetic porewater solution that matched as closely as possible the in situ porewater chemistry (Pearson et al., 2003). This procedure was aimed at minimising osmotic flow effects and shale swelling. Helium gas was used during the gas pressure test stages.

The water and gas permeameter tests performed by BGS were conducted with two core samples from Benken (OPA-1 and OPA-2). Flow direction was parallel and normal to the bedding, respectively. In the following sections, the results of test OPA-1 with flow normal to bedding will be discussed in greater detail. 

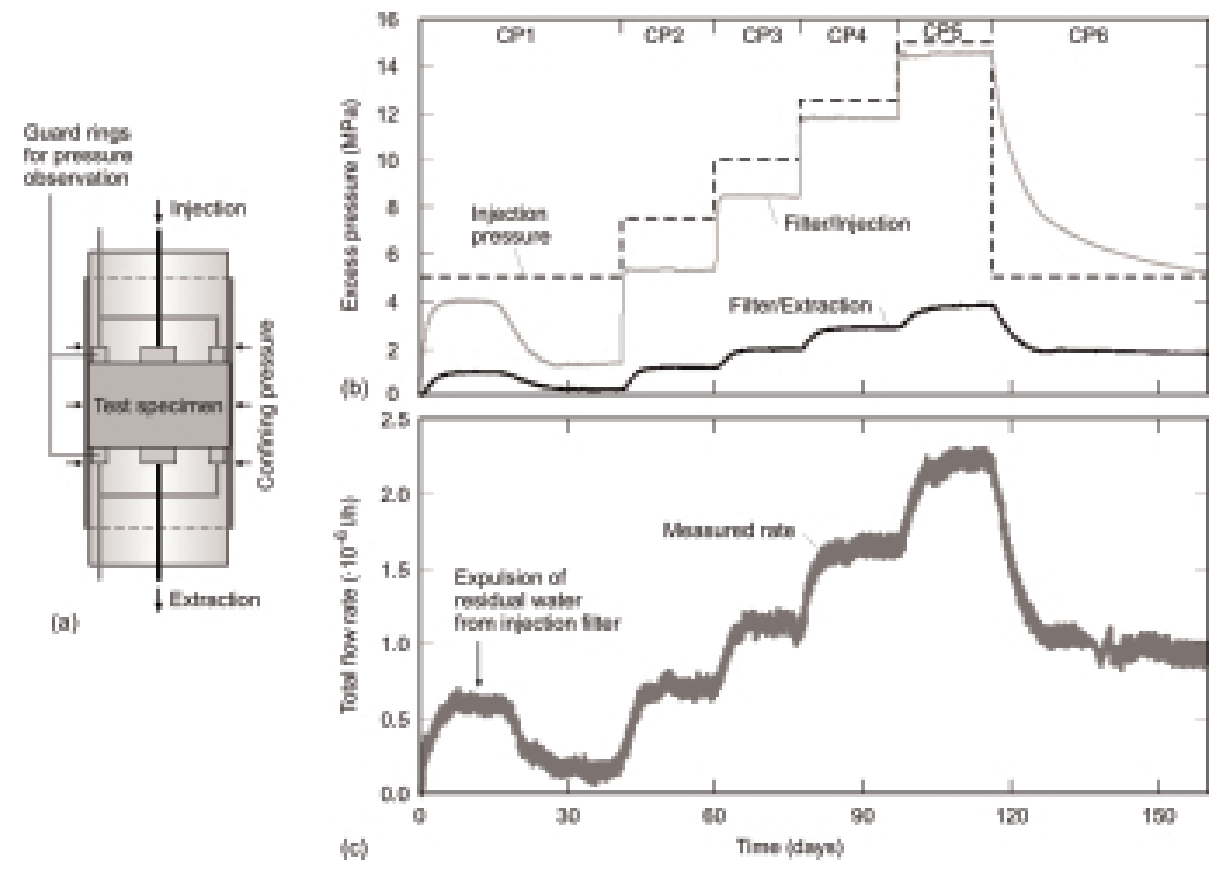

Figure 5

Gas permeability measurements on an Opalinus Clay core sample from the Benken borehole: a) sketch of the isostatic cell containing the test specimen; and $(b+c)$ pressure and flow transients during gas testing (Nagra, 2002a).

During the equilibration stage of 6 days, an isotropic confining stress of 21.0 MPa was applied to the specimen and a fixed backpressure of 5.0 MPa applied to all four filters. Subsequently, a constant rate water injection was established for a period of 57 days, followed by a pressure recovery stage of 48 days. Numerical analysis of the entire hydraulic test sequence (water injection and pressure recovery) provided estimates of intrinsic permeability parallel to the bedding in the range $3-8 \times 10^{-21} \mathrm{~m}^{2}$ and $5-7 \times 10^{-22} \mathrm{~m}^{2}$ normal to bedding, suggesting an anisotropy ratio of approximately 10 . Specific storage estimates ranged between $1-2 \times 10^{-5} \mathrm{~m}^{-1}$.

At the end of the recovery phase, the aqueous solution in the injection system was replaced with helium in order to undertake the constant gas pressure stage $(\mathrm{CP})$. The gas pressure phase consisted of a sequence of 6 pressure stages CP1CP6 as shown in Figure 5b. Upon pressurisation with gas at a pressure of $10 \mathrm{MPa}$, both guard-ring pressures increased during the early time period of $\mathrm{CP} 1$ and a small emergent flow was detected from the specimen, levelling out at $0.6 \mu \mathrm{l} / \mathrm{h}$ after 8 days. The emergent flow can be explained as a slug of water displaced from the pore space of the inlet filter by the pressurised helium. After 15 days, the upstream guard-ring pressure began to drop and, by 28 days, this pressure had fallen to 1.2 MPa above the backpressure. It then rose a little, reaching a final pressure of $6.4 \mathrm{MPa}$ by the end of the first gas test stage (an elapsed time of 41 days). The downstream guard-ring pressure and outgoing flux also began to decrease after around 18 days, reaching a final asymptote of 5.2 MPa and $0.2 \mu \mathrm{l} / \mathrm{h}$. Since the emergent flow from the specimen at the end of the CP1 stage was at least partially gas, this clearly demonstrates that the excess gas pressure at breakthrough had been exceeded and that the value of this quantity is less than 5.0 MPa.

Subsequently, gas pressure in the injection system was raised in a series of 2.5 MPa steps (stages CP2-CP5), reaching a final pressure of $20.0 \mathrm{MPa}$. Outgoing flow rate and guard-ring pressures were monitored over each test stage. Comparison of the flow rates at the end of stages CP1 and CP6 with 10.0 MPa upstream gas pressure reveals a significant increase in gas permeability. This observation can be explained by the desaturation of the sample during the gas injection phase according to the relative permeability relationship (Eq. 3). Further evidence for the process of progressive water displacement is obtained by careful analysis of the cumulative volumetric outflow. Even though the experimental set-up did not allow for a separation of gas and water outflow during testing, an a posteriori determination of cumulative gas flow was feasible. At the time of decommissioning of the test, the backpressure syringe pump was found to contain $0.1 \mathrm{ml}$ of free helium at a pressure of $5.0 \mathrm{MPa}$, corresponding to about $2 \%$ of the cumulative volumetric outflow. In other words, $98 \%$ of the total volumetric outflow can be attributed to expelled porewater from the sample and the filters. The low amount of gas in the outlet indicates that 
quasi-stationary flow conditions along the specimen had not been established after 6 months of gas injection; the injected gas did still displace the porewater from the sample and/or accumulate in the guard filters.

The second test with core sample OPA-2 (flow direction parallel to the bedding) revealed marked differences both in hydraulic and gas transport behaviour, although a similar test procedure was adopted. The hydraulic characterisation indicated a more or less isotropic permeability of about $3 \times 10^{-22} \mathrm{~m}^{2}$. The gas entry pressure was found to be between 7.5 and 10.0 MPa. The most significant difference, however, was seen in the cumulative gas flow. At the time of decommissioning of the test, the backpressure syringe pump was found to contain $5.2 \mathrm{ml}$ of free helium at a pressure of 5.0 MPa, suggesting that the predominant flow was gas moving along the bedding planes. Post-test measurements suggest a gas saturation of around $7 \%$ at the completion of testing.

A total of four water and gas permeameter tests were conducted by SCK.CEN (summary of test results in Marschall et al. 2003) with core samples from the Mont Terri Rock Laboratory (sample identifications BED-B3 06, BFP16 , BED-C5/7 and BWS-E4 06). The confining pressure was $6 \mathrm{MPa}$ and the downstream porewater pressure was $2 \mathrm{MPa}$, corresponding to the in situ conditions at Mont Terri with an overburden $<300 \mathrm{~m}$. One core sample each was subjected to flow parallel and perpendicular to bedding. The flow direction for the other two samples was oblique to bedding. The core samples were saturated with synthetic porewater before the water / gas injection phase started (equilibration phase). As for the BGS experiments, each test started with a hydrotest stage to determine the intrinsic permeability. Subsequently, the gas injection phase was initiated as a constant pumping rate. The gas injection periods ranged from 3 to 8 months. The intrinsic permeabilities to water were consistently in the range of $1-2 \times 10^{-20} \mathrm{~m}^{2}$, with the exception of sample BED-B3 06. This specimen was damaged during the sample preparation process and exhibited a visible fracture in the flow direction. The measured gas entry pressures are all $<0.5 \mathrm{MPa}(c f$. Table 2). The gas saturation of the core samples after the gas injection phase was determined when decommissioning the tests. The reported values $S_{g}=1-S_{w}$ are typically below $10 \%$; in the case of sample BED-B3 06, the upper limit of gas saturation was determined to be $<0.22$.

Before-and-after measurements of hydraulic conductivity were performed on sample BWS-E4 06. Within the uncertainty limits of the measuring technique, a hydraulic test after gas injection exhibits the same conductivity as one done before gas testing $\left(2 \times 10^{-20} \mathrm{~m}^{2}\right)$.

\section{FIELD INVESTIGATIONS}

Packer tests in boreholes have been the main source of field data contributing to the characterisation of gas transport properties in the Opalinus Clay. The general test procedure comprises a combination of hydrotest, gas injection and pressure recovery sequences. A typical test configuration consists of a short straddle double packer system as shown in Figure 6. After packer inflation, the hydrotest sequence is started. The purpose of this sequence is a comprehensive hydraulic characterisation of the formation with particular emphasis on flow model identification and estimation of hydraulic conductivity, storage coefficient and hydraulic head. At the end of the hydraulic test sequence, when the interval pressure has recovered towards the static formation pressure, the fluid in the test interval is replaced by gas. The subsequent gas injection phase may be implemented as an event at constant flow rate ("gas threshold pressure test") or as a multi-step constant head event. Usually, in situ gas tests are conducted with nitrogen. The final stage of gas testing is

TABLE 2

Overview of gas permeameter tests with core specimens from Benken and Mont Terri

\begin{tabular}{l|c|c|c|c}
\hline Core sample & $\begin{array}{c}\text { Injection period } \\
(\mathrm{d})\end{array}$ & $\begin{array}{c}\text { Direction of flow relative } \\
\text { to bedding }\end{array}$ & $\begin{array}{c}\text { Intrinsic permeability } \\
\left(\mathrm{m}^{2}\right)\end{array}$ & $\begin{array}{c}\text { Gas entry pressure } p_{a e} \\
(\mathrm{MPa})\end{array}$ \\
\hline & & & & $\sim 4$ \\
\hline OPA-1 & 140 & $90^{\circ}$ & $\begin{array}{c}k_{p}=3-6 \times 10^{-21} \\
k_{n}=5-7 \times 10^{-2}\end{array}$ & $7.5-10$ \\
\hline OPA-2 & 120 & $0^{\circ}$ & $3 \times 10^{-21}$ & $<0.03$ \\
\hline BED-B3 06 ${ }^{(\text {b) }}$ & 60 & $0^{\circ}$ & $2 \times 10^{-18}$ & 0.5 \\
\hline BFP 16 & 110 & $50^{\circ}$ & $1.5 \times 10^{-20}$ & 0.2 \\
\hline BWS-E4 06 & 180 & $90^{\circ}$ & $2 \times 10^{-20}$ & 0.2 \\
\hline BED-C5/7 & 174 & $35^{\circ}$ & $2 \times 10^{-20}$ & \\
\hline
\end{tabular}

a: intrinsic permeability: $k_{p}$ parallel to bedding, $k_{n}$ normal to bedding.

b: core sample is not representative of undisturbed Opalinus Clay (visible fracture in flow direction). 

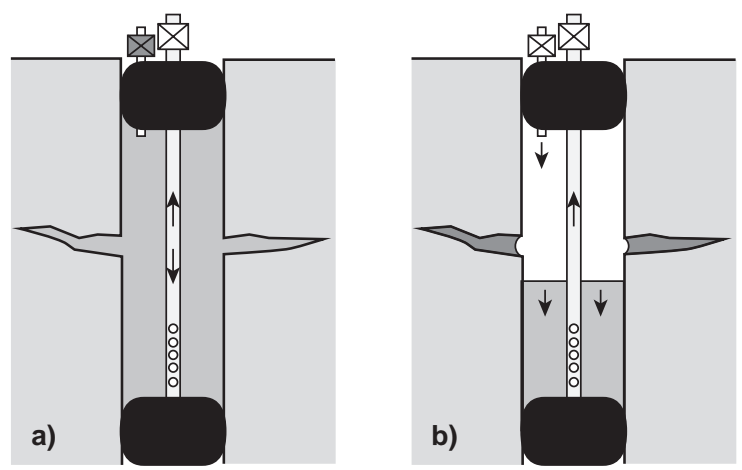

Valve closed
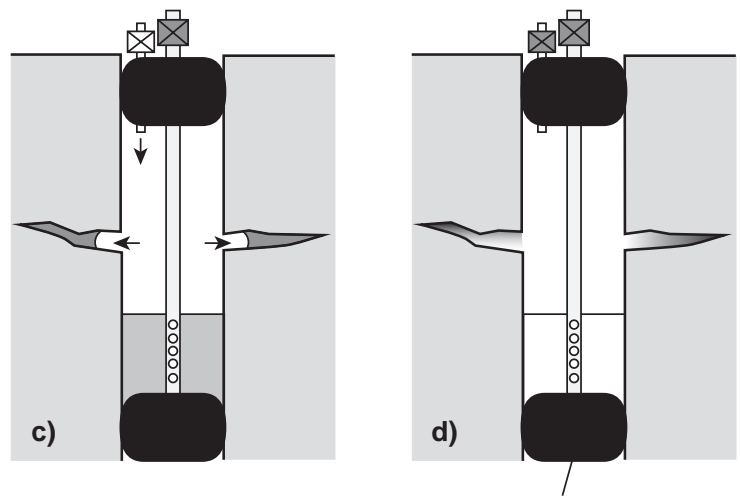

Packer

Figure 6

Gas threshold pressure testing in boreholes - test configuration and procedure: a) hydrotest sequence; b) water/gas displacement DISP; c) gas injection phase GRI; and d) gas pressure recovery phase GRIS.

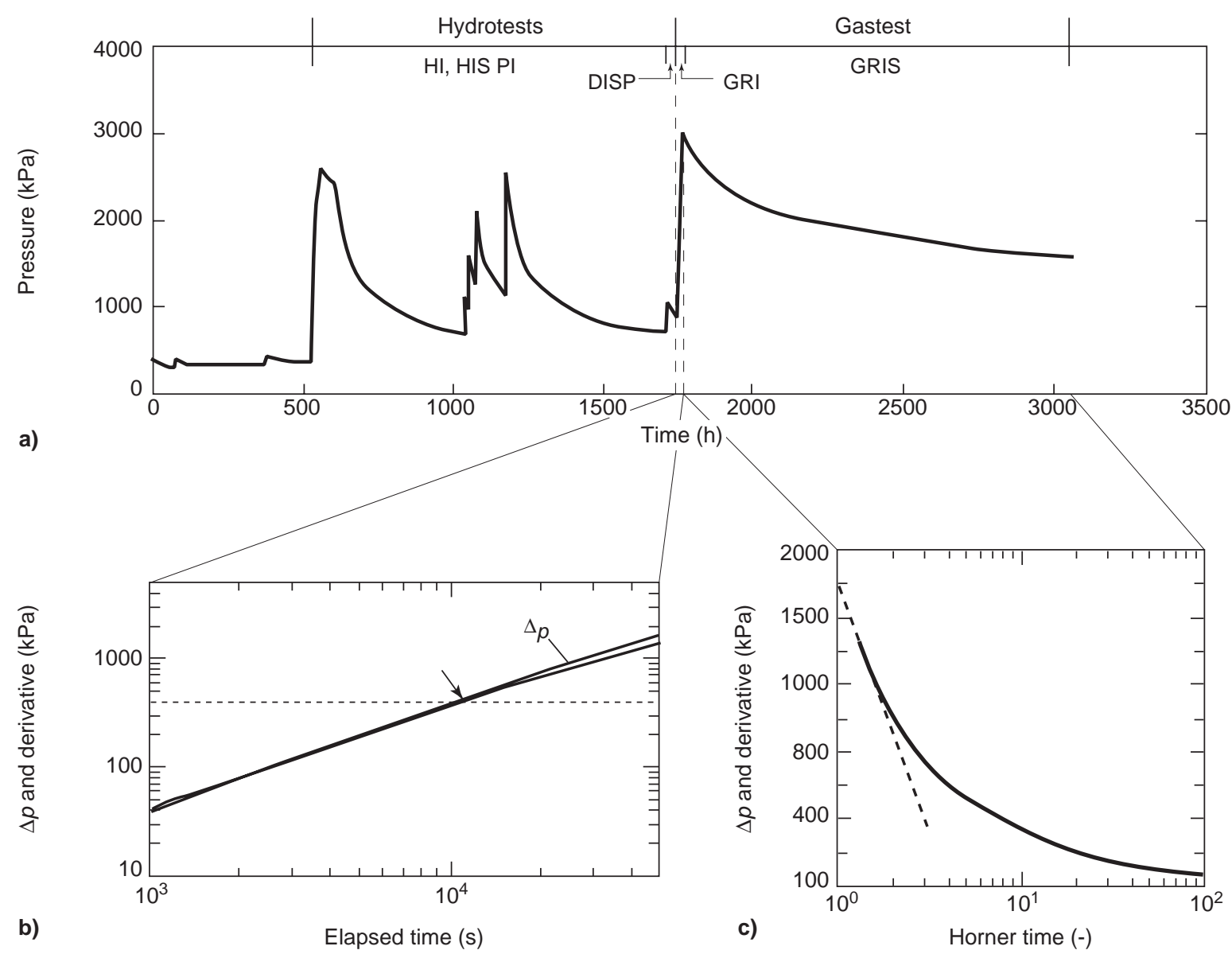

Figure 7

Gas threshold pressure test GP-4 at Mont Terri: a) entire test phase comprising a hydrotest and a gas test sequence; b) log-log derivative plot of the GRI phase; and c) Horner plot of the GRIS phase. 
a shut-in followed by a long-term pressure recovery phase. The primary purpose of the gas test sequence is the determination of the gas entry pressure of the formation. If the test is designed to comprise an extended gas injection phase, further gas transport properties can be estimated, such as the shape factors of the capillary pressure and relative permeability relationships (Senger et al., 1998). At Mont Terri, gas injection experiments were complemented by hydraulic and geomechanical crosshole observations, intended to investigate coupled hydromechanical processes in the vicinity of the injection borehole.

In situ gas tests were conducted at Mont Terri and in the investigation borehole at Benken. Three examples are presented in the following sections, highlighting the current state of conceptual understanding of gas transport mechanisms in the Opalinus Clay. The results of field testing are summarised.

Beyond packer testing in boreholes, empirical observations were made in the Mont Terri Rock Laboratory, demonstrating the evolution of an unsaturated zone around the ventilated tunnels up to a depth of 1-2 m. These studies provide further insight towards broader understanding of multiphase flow processes in argillaceous rock. Recently, the EU-funded research project "Ventilation Experiment" has been launched as part of the Mont Terri project, with special focus on quantitative characterisation of the unsaturated zone (EC contract FIKW-CT2001-00126).

\subsection{Gas Threshold Pressure Test BGP-4}

The gas threshold pressure test BGP-4 in the Mont Terri Rock Laboratory represents a typical example of a gas test that has been analysed with state-of-the-art interpretation tools (Marschall et al., 2003). The test took place in a borehole which intersects a fault zone of several metres thickness. The pressure transients of the entire test phase are presented in Figure 7. Comprehensive hydraulic testing was performed with an unintended short constant head/recovery event at the end of the test phase. Subsequently, a constant rate gas injection was initiated; the starting pressure level $(0.85 \mathrm{MPa})$ is far above the static formation pressure $(0.35 \mathrm{MPa})$. The gas injection was maintained for $19 \mathrm{~h}$, followed by a recovery period of about 60 days. During the injection period, the pressure rose steadily from $0.85 \mathrm{MPa}$ to about $3 \mathrm{MPa}$. During the subsequent shut-in period the pressure fell off to about 1.5 MPa.

The hydrotest sequence was interpreted using a combination of diagnostic analysis, inverse parameter estimation and subsequent uncertainty analysis (summary presented in Marschall et al., 2003). The flow model used for the analysis was a homogeneous radial system of infinite lateral extent with constant wellbore storage. The fitting parameters were hydraulic conductivity, storage coefficient, static formation pressure and wellbore storage coefficient. The overall match of the hydrotest sequence was excellent and fitting parameters were remarkably well constrained; the estimated hydraulic conductivity was $2 \times 10^{-13} \mathrm{~m} / \mathrm{s}$, the storage coefficient was $3 \times 10^{-5} \mathrm{~m}^{-1}$ and the static formation pressure $p_{f}$ ranged between 0.347 and $0.350 \mathrm{MPa}$.

The interpretation of the gas test sequence followed an approach by Senger et al. (1998), consisting of diagnostic analyses and numerical simulations with a multiphase flow model (summary presented in Marschall et al., 2003). The diagnostic analyses are based on a so-called log-log derivative plot of the gas injection phase and a Horner representation of the pressure recovery phase (Horne, 1995). Assuming an initial pressure $p_{i}$, a linear increase of interval pressure $p$ is seen during the wellbore storage dominated early time of gas injection. When the gas entry pressure is reached, the interval pressure begins to deviate from the linear trend, because gas is being released into the rock formation. On the log-log derivative plot, the graphs of pressure change $\Delta p=\left(p-p_{i}\right)$ and pressure derivative $\partial(\Delta p) / \partial(\log t)$ begin to deviate at this point. For gas test BGP-4, the estimated gas entry pressure is about $0.4 \mathrm{MPa}$, assuming the initial pressure $p_{i}$ remained constant at $0.85 \mathrm{MPa}$ (Fig. 7 b).

The Horner plot for the gas pressure recovery phase (Fig. 7c) extrapolates the stabilised interval pressure $p_{s}$ at late times of the recovery phase. Given the maximum gas pressure $p_{\max }$ at the end of the gas injection phase (3 MPa) and the Horner intercept pressure $p_{i c}$ according to Figure 7c $(1.8 \mathrm{MPa})$, the stabilised interval pressure of the recovery phase is $\sim 1.2 \mathrm{MPa}$. Assuming a static formation pressure of $0.35 \mathrm{MPa}$ (determined with the hydrotest analysis), the inferred gas entry pressure is $0.85 \mathrm{MPa}$.

Thus, the diagnostic analyses suggest a gas entry pressure of the formation in the range 0.4-0.8 MPa. The gas injection phase may provide a lower bound, because static formation pressure had not been reached before the start of gas injection. The Horner analysis, on the other hand, delimits the upper range of the parameter spectrum. In order to better constrain the parameter ranges, inverse simulations were performed, covering the entire testing programme with hydrotest and gas test sequences (Marschall et al., 2003). Numerical analyses were conducted with the multiphase flow simulator TOUGH2 (Pruess, 1991) using the van Genuchten/Mualem parametric models for relative permeability and capillary pressure. The fitting parameters were the permeability, the formation compressibility (formation storage coefficient), the wellbore storage, the air entry pressure and the porosity. No inverse estimates of the pore size distribution index and residual water saturation were obtained, as the sensitivity of the pressure to these parameters was found to be low (fixed input values $\left.S_{w r}=0.1, S_{w g}=0, n=2\right)$. A very good match of the data was obtained with low correlation between the fitting parameter and a low degree of parameter uncertainty. The best estimate value of the permeability was about $6 \times 10^{-20} \mathrm{~m}^{2}$ (3 times higher than the single phase analysis of the hydrotest sequence would suggest); the best estimate of 
the gas entry pressure was $0.82 \mathrm{MPa}$. In comparison to the hydrotests, the estimated conductivity is about 3 times higher and the specific storage coefficient 10 times lower. The estimate for the air entry pressure arising from the Horner analysis corresponds very well to the estimate from the inverse simulation. It is worth noting that the adopted conceptual model (homogeneous medium, no gravity segregation) does not account for the characteristic features of gas imbibition into a fully saturated medium, such as fingering due to fluid viscosity differences or to heterogeneities. With this assumption in mind, the simulations suggest a penetration depth of the gas front $<10 \mathrm{~cm}$ into the formation.

\subsection{Gas Threshold Pressure Test O5}

The gas threshold pressure test $\mathrm{O} 5$ in the Benken borehole was located in the centre of the Opalinus Clay formation at a depth of 600.1-603.5 m below ground (Nagra, 2001). The test interval contained a minor fault zone with a thickness of $0.1 \mathrm{~m}$. The test is presented here because its anomalous pressure recovery phase is considered as evidence for dilatancy-controlled gas flow into the rock formation.
Prior to gas testing, the test zone had been subjected to extended hydraulic testing. The interpretation reveals a best estimate hydraulic conductivity of $1 \times 10^{-14} \mathrm{~m} / \mathrm{s}$, with an uncertainty range between $1 \times 10^{-15} \mathrm{~m} / \mathrm{s}$ and $3 \times 10^{-14} \mathrm{~m} / \mathrm{s}$. Furthermore, the analyses indicate distinct porewater overpressures on the level of the test zone, corresponding to a hydraulic head of $\sim 150 \mathrm{~m}$ above hydrostatic conditions.

The pressure transients of the gas test sequence $\mathrm{O} 5$ are shown in Figure 8. After displacement of the test fluid in the test interval by gas (DIS1, DIS2), the first constant rate gas injection phase (GRI1) was initiated at $21 / \mathrm{min}$ (with $\mathrm{N}_{2}$ at standard pressure conditions, STP). The rate was reduced after $0.6 \mathrm{~h}$ to $11 / \mathrm{min}$ (STP) to improve the detection of the gas entry (GRI2). The duration of the GRI2 phase was $35.5 \mathrm{~h}$, with a total pressure change of $4.7 \mathrm{MPa}$ and a final pressure of $11 \mathrm{MPa}$. The injection phase was stopped to avoid the risk of creating gas fractures. The first shut-in phase (GRIS1) lasted $2.8 \mathrm{~h}$, before a third gas injection GRI3 was started at the same injection rate as GRI2. GRI3 was stopped after $2.8 \mathrm{~h}$ at a final pressure of $11.3 \mathrm{MPa}$ and the final shut-in phase GRIS2 was started. Packer pressures and interval pressures of the adjacent zones (bottom hole zone and annulus above the upper packer)

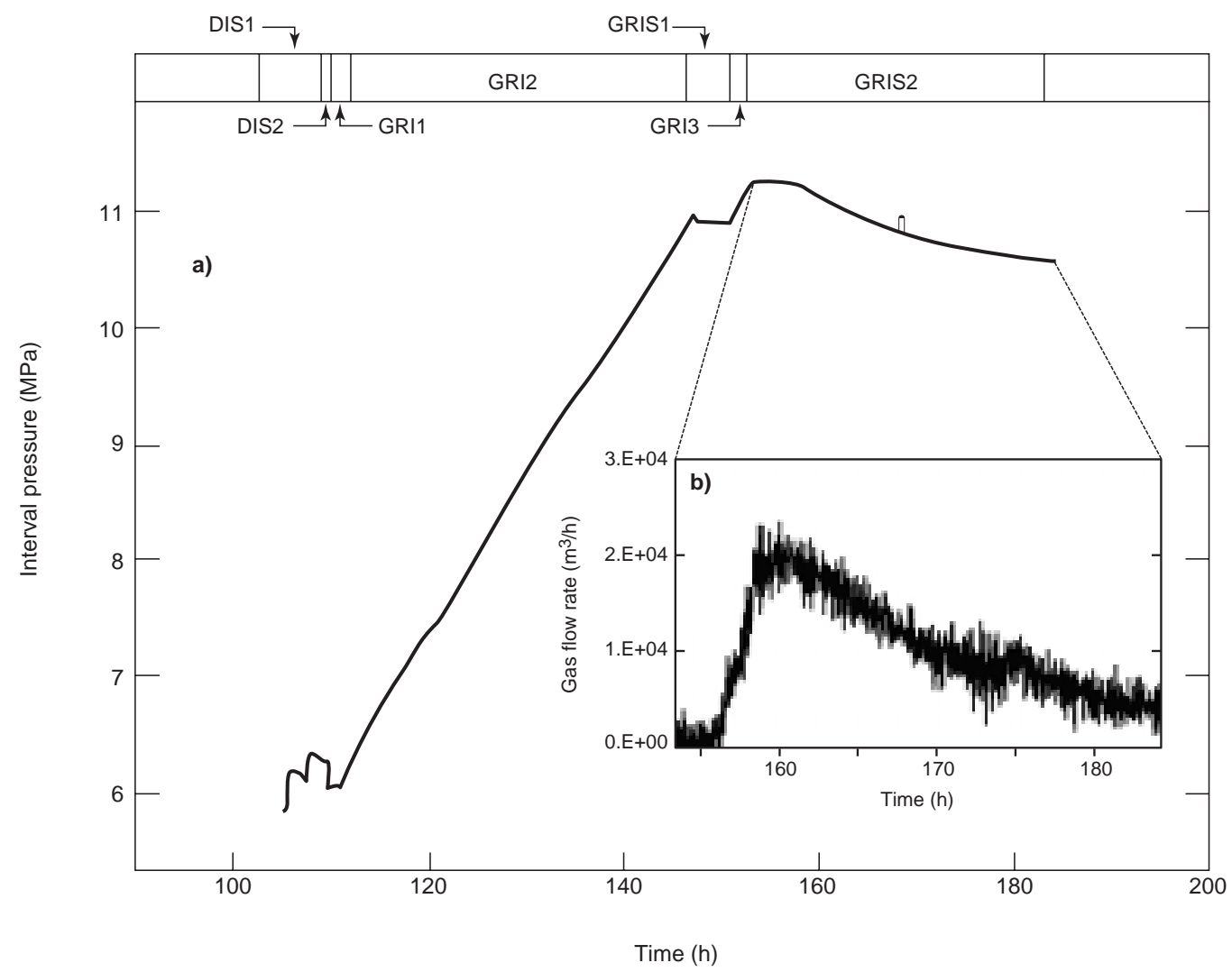

Figure 8

Gas threshold pressure test $\mathrm{O} 5$ in the Benken borehole: a) interval pressure during gas injection and pressure recovery period; and b) calculated gas leak-off into the rock formation (DIS1/DIS2 - water/gas displacement; GRI1/GRI2/GRI3 - constant rate gas injection; GRIS1/GRIS2 - pressure recovery period). 
were monitored during the entire gas test sequence. The transients did not reveal indications for possible packer bypass or other technical problems during testing

The pressure response during the GRI2 phase indicates a minor deviation from unit slope at a gas pressure of $7.2 \mathrm{MPa}$, which may be caused by invasion of gas into a disturbed zone around the borehole ("inner zone"). Above 8.5 MPa, the slope of the pressure curve remains constant until the shut-in is reached. The subsequent GRIS1 sequence results in nearly constant pressures, corroborating a closed system without noticeable gas transport into the outer zone. The pressure response during the subsequent GRI3 also shows a linear increase. The initial response during GRIS2 is characterised by, again, nearly constant pressures, which start to decline after about $155 \mathrm{~h}$, indicating pressure dissipation most likely associated with gas movement into the formation.

The anomalous pressure response during GRIS2, when pressure remains approximately constant initially but starts to decline after about $155 \mathrm{~h}$, is seen as an indication of the onset of dilatancy-controlled gas flow into the formation. The Horner plot analysis of GRIS2 suggests a gas entry pressure value of 4.3 MPa (Nagra, 2002a), which is within a reasonable range compared to the results of the laboratory experiments (cf. Table 2, tests OPA-1 and OPA-2). However, the signature of the GRIS2 phase does not match the expected response of a standard two-phase flow system: the initial phase with nearly constant pressure, followed by a rather rapid decline, suggests that the formation cannot hold the gas pressure for a long time and starts to leak. The leak-off rate into the formation during GRIS2 is shown in Figure 8b, indicating a gradual increase in gas flow during the early part of GRIS2, when pressures were relatively flat (at about 153$156 \mathrm{~h}$ ). The maximum volumetric flow rate of $2 \times 10^{-4} \mathrm{~m}^{3} / \mathrm{h}$ corresponds to the onset of the steep pressure decline starting at about $158 \mathrm{~h}$, with a subsequent gradual decrease. Given the radius and the length of the test interval, the volumetric gas flow rate can be converted into a specific mass flux through the borehole wall. As a rough estimate, the rock formation accommodates a specific gas flux in the order of magnitude of $1 \times 10^{-5} \mathrm{~m}^{3} \mathrm{~m}^{-2} \mathrm{~s}^{-1}$ (STP)—the underlying gas transport mechanism can be either two-phase flow or dilatancy-controlled gas flow. The process of classical hydro- or gas fracturing, however, can be ruled out, because the formation of a macroscopic tensile fracture would be associated with a characteristic and completely different signature in the pressure transients.

\subsection{Multi-Step Gas Injection Test GS-2}

The multi-step gas test GS-2 in the Mont Terri Rock Laboratory was explicitly designed for monitoring hydromechanical responses of the rock formation to a gas injection event (Marschall et al., 2003). The experimental layout comprised a total of 4 boreholes at a distance of less than $2 \mathrm{~m}$ from each other, two of them equipped with triple-packer systems and the others instrumented with multiple extensometers for observations of the axial deformation (Fig. 9). The test lasted for a total of 30 days and incorporated a testing sequence with three pressure levels (Marschall et al., 2003). Before testing commenced in the injection borehole, the borehole fluid in the test interval was replaced with nitrogen gas. The gas injection was started with a gas pulse injection pretest (PRE). During this phase, a leak was detected in the surface equipment, which explains the strong pressure recovery. The pressure in the test interval was then increased stepwise to $1175 \mathrm{kPa}$ (PI1), $1916 \mathrm{kPa}$ (PI2) and $2776 \mathrm{kPa}$ (PI3), followed by a pressure release and recovery stage (PW1). Figure 9 shows the development of the interval pressure in the gas injection borehole, as well as the deformation in the observation borehole at a distance of $0.8 \mathrm{~m}$. For the pressure step PI1, the formation appears practically impermeable to gas as the gas entry pressure has not yet been reached. Low leak-off rates are observed during PI2 without any significant deformation in the adjacent extensometer boreholes. Finally, the highest pressure level PI3 is characterised by a distinct gas leak-off. The extensometer, placed in the midinterval of the observation borehole, shows significant extension of about $20 \mu \mathrm{m} / \mathrm{m}$ which is not reversible during the pressure release phase PW1. Correspondingly, during PI3 the two adjacent extensometer intervals exhibit a tendency for contraction, which can be explained as a compensation process in response to the extension of the central interval.

Together with a hydrotest sequence that had been carried out as a precursor, the gas test was analysed with the multiphase flow simulator TOUGH2 (results presented in Marschall et al., 2003 and Nagra, 2002a). The results of the inverse simulation indicate a noticeable increase in permeability between the hydrotest sequences $\left(k=2.2 \times 10^{-20} \mathrm{~m}^{2}\right)$ and the third pressure step PI 3 of the gas test $\left(k=5.4 \times 10^{-20} \mathrm{~m}^{2}\right)$. The two-phase flow parameters exhibited strong cross-correlation and are therefore not very reliable. By visual inspection of the pressure transients in Figure 9, the gas entry pressure is inferred to be in the order of $0.5 \mathrm{MPa}$. This value corresponds to the onset of gas flow at the pressure level of PI2.

The onset of extension in the adjacent monitoring interval at elevated gas pressure (PI3), together with a noticeable increase of intrinsic permeability, suggests that the gas injection experiment GS-2 has explored two different gas transport regimes: classical two-phase flow behaviour during PI2 when the onset of gas leak-off is monitored and dilatancycontrolled gas flow during PI3. After termination of the gas test sequence and resaturation of the test interval, a series of hydrofrac experiments were conducted in borehole BGS-2 (Marschall et al., 2003). Three attempts at very high fluid injection rates were necessary to create the hydrofrac. The frac was characterised by a transmissivity that was more than 5 orders of magnitude higher than the interval transmissivity before fracturing. The hydrofrac analysis exhibited a frac 
a)
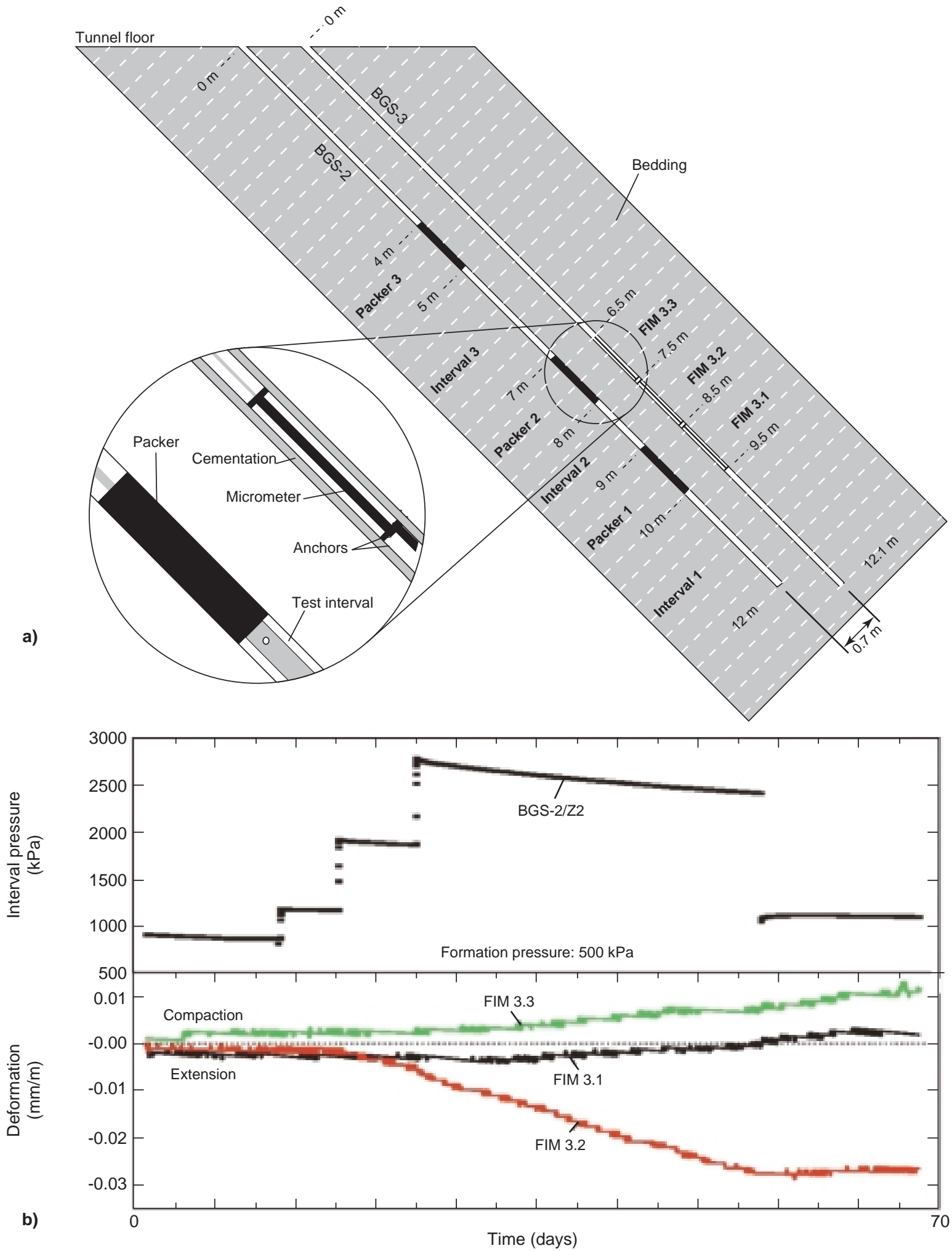

Figure 9

Multi-step gas injection test GS-2 at Mont Terri: a) hydromechanical instrumentation of the injection and monitoring boreholes; b) transients of interval pressure in the injection borehole and axial deformation in the adjacent monitoring borehole. 
pressure of $\sim 9 \mathrm{MPa}$, refrac pressures of $\sim 5 \mathrm{MPa}$ and a shutin pressure of $\sim 4.2 \mathrm{MPa}$. A detailed interpretation of the hydrofrac sequence revealed a complex fracture geometry with both tensile and shear fractures as well as branches (Daneshy et al., 2004).

\subsection{Summary of Field Results}

A total of three gas threshold pressure tests and two long-term gas injection tests were conducted in the Opalinus Clay formation. The length of the test intervals between $1 \mathrm{~m}$ and $4.5 \mathrm{~m}$ may be indicative for the scale of investigation. Specific gas flow rates (gas flow per circumferential area of the test interval) were determined for each test to compare the gas leak-off into the rock formation. The specific gas flow rates covered a wide spectrum between $7 \times 10^{-9} \mathrm{~m}^{3} \mathrm{~m}^{-2} \mathrm{~s}^{-1}$ and $1 \times 10^{-5} \mathrm{~m}^{3} \mathrm{~m}^{-2} \mathrm{~s}^{-1}(\mathrm{STP})$. Intrinsic permeability ranged between $1 \times 10^{-21} \mathrm{~m}^{2}$ and $6 \times 10^{-20} \mathrm{~m}^{2}$. A gas entry pressure > $5 \mathrm{MPa}$ was inferred for the gas test at Benken; the tests in the Mont Terri Rock Laboratory, however, exhibit significantly lower values between 0.4 and 1.0 MPa. Table 3 presents a summary of the results of field testing.

\section{DISCUSSION}

Gas transport through the Opalinus Clay is strongly controlled by the microstructural features of the rock mass. Imbibition of a gas phase into the existing pore space of the rock is restricted to the connected system of macropores (> $25 \mathrm{~nm}$ ) displacement of water from the meso- and micropores would require gas pressures that exceed the mechanical strength of the rock and consequently lead to rock failure. As part of the rock characterisation programme on Opalinus Clay, microstructural investigations were conducted with different laboratory methods. The studies revealed consistent estimates of the fraction of macropores in the range 10-30\%.

Capillary pressure curves were derived from microstructural investigations and from controlled suction experiments. The data exhibit the typical shape of the van Genuchten parametric model with a steep rise of capillary pressure in the range of high water saturation. According to Figure 4, when a fully saturated rock sample is subjected to an excess gas pressure of $10 \mathrm{MPa}$ (i.e. gas pressure above porewater pressure), the amount of displaced porewater is about $10-20 \%$, corresponding to a water saturation $S_{w}$ between 0.8 and 0.9 . For the stress state of the Opalinus Clay in the Zürcher Weinland $\left(\sigma_{3}=15-16 \mathrm{MPa}, p_{w}=6.5-8 \mathrm{MPa}\right)$, the excess gas pressures of $10 \mathrm{MPa}$ can be viewed as the upper limit that the formation can sustain without rupture.

A distinct difference is observed between water desorption and adsorption, indicating a strong hysteresis between the gas imbibition and resaturation processes, respectively. The set of capillary pressure curves exhibits a wide uncertainty range. This spread may be attributed in part to the fact that the different experimental methods provide slightly different estimates of capillary pressure, since each method samples the pore space in a different way. On the other hand, recalling the mineralogical and structural variability of the Opalinus Clay on the microscopic scale ( $c$ f. Fig. 1), the wide uncertainty range of the capillary curves is no surprise: flow of a nonwetting fluid through a saturated porous medium is known to be a transport process that maps and exploits the heterogeneities of the connected pore space. Notably, the aforementioned hysteretic behaviour is also viewed as a consequence of the microscale heterogeneity of the rock. In the present study, the following parameter ranges were used to represent the two-phase flow behaviour of the Opalinus Clay: $5 \mathrm{MPa} \leq \alpha^{-1} \leq 21 \mathrm{MPa}$, $0 \leq S_{w r} \leq 0.5,0 \leq S_{g r} \leq 0.05$ and $1.5 \leq n \leq 2$.

The in situ gas threshold pressure tests and gas permeability tests with core specimens indicate that the Opalinus Clay exhibits a correlation between intrinsic permeability and gas entry pressure. Similar correlations have been found for other rock formations and predictor relationships based on intrinsic permeability have been developed. Figure 10 shows a compilation of laboratory data from Davies (1991) and a survey of oil industry data (Ingram et al., 1997; Horseman, 2001) - the results from Mont Terri and Benken are added. A clear trend between entry pressure and intrinsic permeability is seen, but the spread of the data is enormous. The gas entry pressures from Benken fit reasonably well to the Davies relationship, whereas the data base of Ingram et al. (1997) would suggest considerably higher values. The entry pressures determined for the Mont Terri Rock Laboratory are significantly below the Davies relationship.

TABLE 3

Gas injection experiments in the Benken borehole and at the Mont Terri Rock Laboratory

\begin{tabular}{l|c|c|c|c}
\hline Test & Injection period $(\mathrm{h})$ & $\begin{array}{c}\text { Specific gas flow rate } \\
\left(\mathrm{m}^{3} \mathrm{~m}^{-2} \mathrm{~s}^{-1} \mathrm{STP}\right)\end{array}$ & $\begin{array}{c}\text { Intrinsic permeability } k \\
\left(\mathrm{~m}^{2}\right)\end{array}$ & $\begin{array}{c}\text { Gas entry pressure } p_{a e} \\
(\mathrm{MPa})\end{array}$ \\
\hline Benken O5 (GTP) & $\sim 38$ & $1 \times 10^{-5}$ & $1 \times 10^{-21}$ & $>5$ \\
Mont Terri GS-2 (MSI) & $\sim 700$ & variable & $2-5 \times 10^{-20}$ & $\sim 0.5$ \\
Mont Terri GP-4 (GTP) & $\sim 18$ & $7 \times 10^{-9}$ & $2-6 \times 10^{-20}$ & $0.4-0.8$ \\
Mont Terri GP-6 (GTP/MSI) & $\sim 150$ & $2 \times 10^{-8}$ & $2 \times 10^{-20}$ & $\sim 1.0$ \\
\hline
\end{tabular}




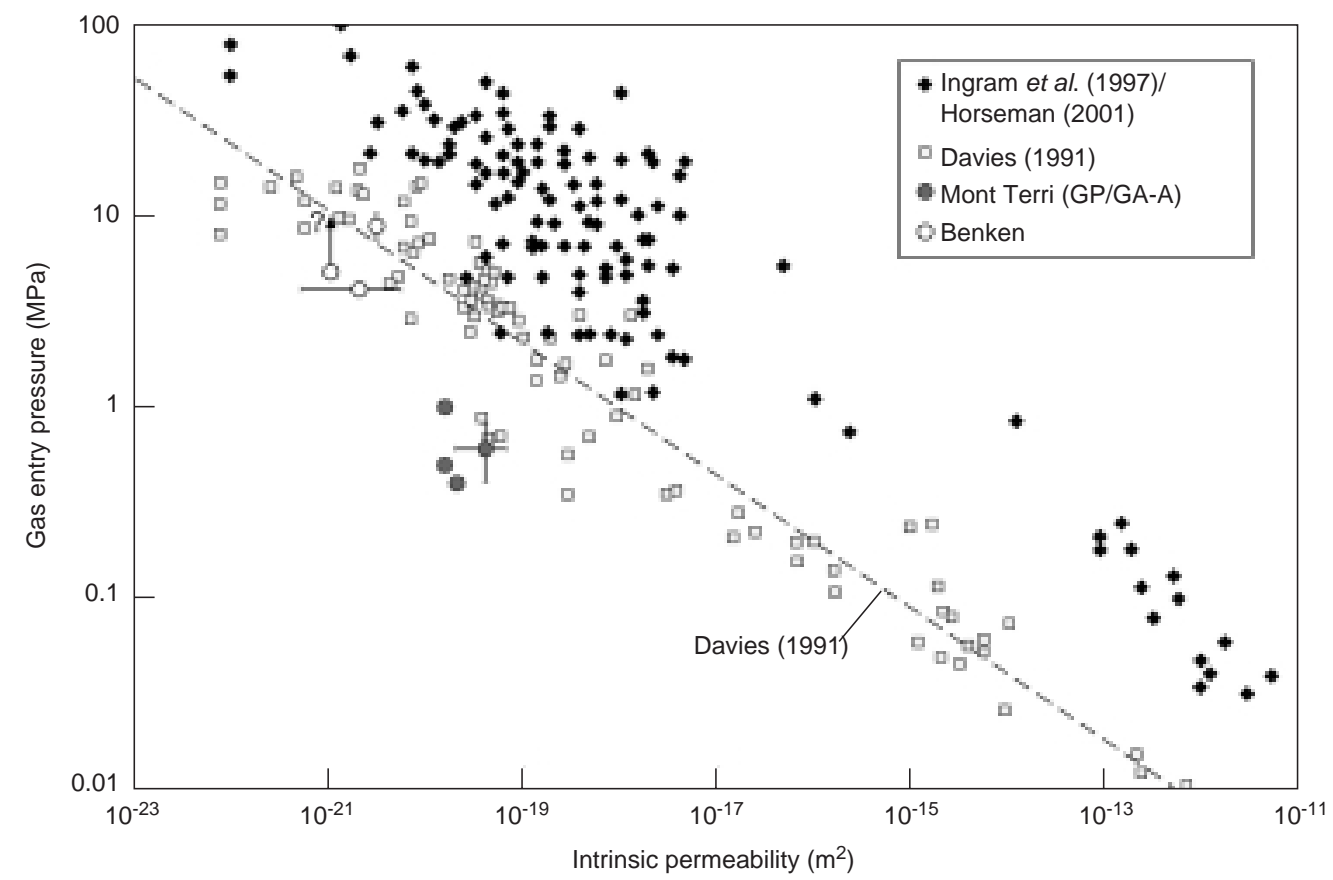

Figure 10

Relationship between gas entry pressure and intrinsic permeability for various low permeability rock formations (claystones, shales, sandstone). The results from Benken and Mont Terri have been added to the original compilations of Davies (1991) and Ingram et al. (1997), referenced by Horseman (2001).

The reasons for the large scatter in Figure 10 are twofold. First, the entry pressure-permeability correlation does not consider the microstructural and mineralogical features of the rock. It is obvious that the pore size distribution, the smallscale heterogeneity, intrinsic anisotropy, clay content and specific surface are determining factors for the gas entry pressure, which cannot be represented appropriately by a simplifying $p_{a e}-k$ relationship. On the other hand, the correlation does not reflect the site-specific conditions that may determine the onset of gas flow, such as in situ stress and porewater pressure. Further site-specific characteristics such as burial history, diagenetic processes and the tectonic regime need to be considered. When in situ stress is low due to low overburden (e.g. Mont Terri), the onset of dilatancycontrolled gas entry into the rock formation may be expected at gas pressures that are below the capillary entry of the intact rock. Movement of gas along interconnected microcrack networks associated with rock dilatation may explain the low entry pressure values observed at Mont Terri.

\section{CONCLUSIONS}

Summarising the achievements of this study on gas transport properties of the Opalinus Clay, the following conclusions are drawn:

- Multiple evidence on different experimental scales was found for visco-capillary flow of gas in the existing pore space of the Opalinus Clay, suggesting that classical flow concepts of immiscible displacement in porous media can be applied to such problems when the gas entry pressure (i.e. capillary threshold pressure) is less than the minimum principal effective stress acting within the rock.

- In contrast to classical porous media, gas transport through the Opalinus Clay does not cause a major desaturation of the rock. Under in situ stress and pore pressure conditions, the water saturation will not decrease below a range of 0.7-0.9.

- The mineralogical variability and microstructural heterogeneity of the Opalinus Clay suggest that gas transport is strongly focused along preferential flow paths. Further research work is required to constrain the inherent parameter uncertainty of the two-phase flow properties and to define appropriate representative elementary volumes for gas transport properties.

- Evidence was found for dilatancy-controlled gas transport at elevated gas pressures and in rock damaged by shear deformation and destressing. Characteristic features of this gas transport mechanism are the enhancement of gas permeability at elevated gas injection pressures and dilatant strains in the vicinity of a gas injection borehole.

- As long as the gas pressure build-up at the locus of gas generation is slow, visco-capillary two-phase flow and dilatancy-controlled gas flow represent efficient transport mechanisms to accommodate gas flow in the Opalinus 
Clay. In this context, "slow" means that gas generation is largely balanced by porewater displacement (drained geomechanical conditions). The determining factor for distinguishing between "slow" and "rapid" gas pressure build-up is the hydraulic diffusivity of the rock (ratio between storage coefficient and hydraulic conductivity).

- Hydraulic fracturing experiments have been conducted at Mont Terri. The tests demonstrate that high fluid pressures and high injection rates are required to create tensile fractures in Opalinus Clay (hydro- or gasfracs). The pressure build-up rates in the test interval are many orders of magnitude higher than the gas pressure build-up rates expected in the disposal tunnels of a closed radwaste repository. Hydrofracturing and gas fracturing are therefore excluded as possible risks for repository performance.

Future investigations on gas transport in the Opalinus Clay will aim at gaining an improved understanding of the most relevant transport mechanisms, namely two-phase flow and dilatancy-controlled gas flow. In ultra-low permeability formations, the classical two-phase flow concepts may need further refinement and adaptation - in particular with respect to the relative permeability formulation and the anisotropic permeability. Additional experimental evidence on the laboratory and field scale is required to constrain the existing parameter uncertainty and, on the other hand, to explore new parametric models. The regime of dilatancy-controlled gas flow needs an extended theoretical foundation and further experimental justification. Systematic laboratory experiments with triaxial cells for a wide spectrum of possible stress paths are recommended to gain better insight into the mechanisms which control the appearance of dilatancy dependent permeability changes.

\section{ACKNOWLEDGEMENTS}

The authors would like to thank scientific colleagues, research collaborators and project partners, notably Jon Harrington and David Noy of BGS, Lorenzo Oriz Amaya of SCK.CEN, Bernd Frieg/Nagra, Christian Enachescu/Golder, Jean Croisé/ Colenco, Rainer Senger/Intera and Hans-Rudi Fisch/Solexperts -who have contributed their knowledge, skills and personal energy to the study of gas movement in the Opalinus Clay. We have greatly benefited from intensive discussion within Nagra's R\&D team, in particular Piet Zuidema, Lawrence Johnson, Andreas Gautschi and Peter Blümling.

\section{REFERENCES}

Bear, J. (1972) Dynamics of fluids in porous media, American Elsevier Pub., New York.

Birkhäuser, P., Roth, P., Meier, B. and Naef, H. (2001) 3DSeismik: Räumliche Erkundung der mesozoischen Sedimentschichten im Zürcher Weinland, Nagra Technical Report NTB 00-03, Nagra, Wettingen, Switzerland.
Clayton, C.J. and Hay, S.L. (1994) Gas migration mechanisms from accumulation to surface. Bull. Geol. Soc. Denmark 41, 12-23.

Daneshy, A., Blümling, P., Marschall, P. and Zuidema, P. (2004) Interpretation of Field Experiments and Observation of Fracturing Process. Proc. SPE/Formation Damage Control, SPE 86486, Lafayette, Louisiana.

Davies, P. B. (1991) Evaluation of the role of threshold pressure in controlling flow of waste-generated gas into bedded salt at the Waste Isolation Pilot Plant (WIPP). Sandia Rep. SAND 90-3246, Sandia National Laboratories, Albuquerque, New Mexico.

Dury, O. Fischer, U. and Schulin, R. (1999) A comparison of relative nonwetting-phase permeability models. Water Resour. Res. 35/5, 1481-1493.

Helmig, R. (1997) Multiphase Flow and Transport Processes in the Subsurface. Springer Publ., Berlin.

Harrington, J.F., Horseman, S.T., and Noy, D.J. (2001) Swelling and osmotic flow in a potential host rock. In: Delage, P. (ed.): Proc. of the 6th International Workshop on Key Issues in Waste Isolation Research (KIWIR-2001), Ecole Nationale des Ponts et Chaussées, Paris, France, 28-30 November.

Horne, R.N. (1995) Modern Well Test Analysis. Petroway Inc., Palo Alto, California.

Horseman, S.T. (2001) Gas migration through indurated clays (mudrocks). In: Gas Generation and Migration in Radioactive Waste Disposal. Proc. of the NEA Workshop in Reims 2000, France.

Horseman, S.T., Higgo, J.J.W., Alexander, J. and Harrington, J.F. (1996) Water, gas and solute movement through argillaceous media. Nuclear Energy Agency Rep. CC-96/1, Paris, OECD.

Ingram G.M., Urai, J.L. and Naylor, M.A. (1997) Sealing processes and top seal assessment. In: Hydrocarbon Seals: Importance for Petroleum Exploration and Production (eds. P. Molle-Pedersen and A.G. Koesler) Norwegian Petroleum Society, Special Publication 7, Elsevier, Amsterdam, 165-174.

IUPAC (1997) Compendium of Chemical Terminology. The Gold Book, Second Edition, A. D. McNaught and A. Wilkinson, Blackwell Science, London.

Krooss, B.M., Leythaeuser, D., Schäfer, R.G. (1992) The quantification of diffusive hydrocarbon losses through cap rocks of natural gas reservoirs - a re-evaluation. The American Association of Petroleum Geologists Bulletin 76, 403-406.

Marschall, P., Croisé, J., Schlickenrieder, L., Boisson, J.Y., Vogel, P. and Yamamoto, S. (2003) Synthesis of hydrogeological investigations at the Mont Terri site (Phases 1 - 5). Mont Terri Technical Report TR 2001-02, Geotechn. Inst. Ltd., Bern, Switzerland.

Müller, W.H., Naef, H. and Graf, H.R. (2002) Geologische Entwicklung der Nordschweiz, Neotektonik und Langzeitszenarien Zürcher Weinland. Nagra Technical Report NTB 99-08, Nagra, Wettingen, Switzerland.

Muñoz, J.J., Lloret, A., Alonso, E. (2003) Ventilation Experiment in Opalinus clay - Laboratory Report: Characterization of hydraulic properties under saturated and non saturated conditions. Project Deliverable 4, EC contract FIKW-CT200100126/'EURATOM.' Programme (1998-2002), final project report in preparation.

Nagra (2001) Sondierbohrung Benken - Untersuchungsbericht. Nagra Technical Report NTB 00-01, Nagra, Wettingen, Switzerland.

Nagra (2002a) Projekt Opalinuston - Synthese der geowissenschaftlichen Untersuchungs-ergebnisse. Entsorgungsnachweis für abgebrannte Brennelemente, verglaste hochaktive sowie langlebige mittelaktive Abfälle. Nagra Technical Report NTB 02-03, Nagra, Wettingen, Switzerland.

Nagra (2002b) Project Opalinus Clay: Safety Report. Demonstration of disposal feasibility (Entsorgungsnachweis) for 
spent fuel, vitrified high-level waste and long-lived intermediatelevel waste. Nagra Technical Report NTB 02-05, Nagra, Wettingen, Switzerland.

Nagra (2004) Effects of Post-disposal Gas Generation in a Repository for Spent Fuel, High-level Waste and Long-lived Intermediate Level Waste Sited in Opalinus Clay. Nagra Technical Report NTB 04-06, Nagra, Wettingen, Switzerland.

Pearson, F.J., Arcos, D., Bath, A., Boisson, J.-Y., Fernández, A.M., Gaebler, H.E., Gaucher, E., Gautschi, A., Griffault, L., Hernan, P. and Waber, H.N. (2003) Geochemistry of water in the Opalinus Clay formation at the Mont Terri Rock Laboratory Synthesis Report. Bern, Switzerland, Berichte des Bundesamtes für Geologie und Wasser - Serie Geologie, Nr. 30.

Pruess, K. (1991) TOUGH2-A general-purpose numerical simulator for multiphase fluid and heat flow. Lawrence Berkeley Laboratories, Report LBL-29400, Berkeley, CA.

Schlömer, S., Krooss, B.M. (1997) Experimental characterisation of the hydrocarbon sealing efficiency of cap rocks. Marine and Petroleum Geology 14, 565-580.

Senger, R., Marschall, P. and Lavanchy, J.-M., 1998 Gas Threshold Pressure Tests in Deep Boreholes for Determining
Two-Phase Flow Properties of the Host Rock at the Proposed L/ILW Repository, Switzerland, Mat. Res. Soc., Symp. Proc. Vol. 506, 829-838

Thury, M. \& Bossart, P., eds. (1999) Mont Terri Rock Laboratory: Results of the Hydrogeological, Geochemical, and Geotectonical Experiments performed in 1996 and 1997. Bern, Switzerland, Landeshydrologie und -geologie, Geologische Berichte Nr. 23.

Valko, P. and Economides, M.J. (1997) Hydraulic fracture mechanics. John Wiley, New York.

van Genuchten, M.Th. (1980) A closed-form equation for predicting the hydraulic conductivity of unsaturated soils. Soil Sci. Soc. Am. J., Vol. 44.

Villiéras, F., Michot, L. J., Cases, J. M., Bérend, I., Bardot, F., François, M., Gérard, G. \& Yvon, J. 1997 Static and dynamic studies of the energetic surface heterogeneity of clay minerals. In W. Rudzinski, W.A. Steele \& G. Zgrablich (eds), Equilibria and Dynamics of Gas Adsorption on Heterogeneous Solid Surfaces: 573-623.

Final manuscript received in November 2004 or distributed for profit or commercial advantage and that copies bear this notice and the full citation on the first page. Copyrights for components of this work owned by others than IFP must be honored. Abstracting with credit is permitted. To copy otherwise, to republish, to post on servers, or to redistribute to lists, requires prior specific permission and/or a fee: Request permission from Documentation, Institut français du pétrole, fax. +33147527078 , or revueogst@ifp.fr. 